loạn nhịp thở dẫn đến rối loạn nồng độ $\mathrm{CO} 2$ và O2 trong máu. Trên lâm sàng, bệnh nhân nữ thường biểu hiện lo âu căng thẳng nhiều hơn bệnh nhân nam. Hai triệu chứng sợ mất kiềm chế và sợ bị chết cũng gặp ở bệnh nhân RLLALT nhưng tỉ lê không cao. Trong nhóm này, triệu chứng chứng chóng mặt/không vững/ngất xỉu là một trong những triệu chứng khiến bệnh nhân đển thăm khám và điêu trị tại chuyên khoa Thần kinh.

Nhóm triệu chứng căng thẳng. Hầu hết bệnh nhân trong nghiên cứu có triệu chứng bồn chồn chiếm tỉ lệ 44,1\% (bảng 3.3). Tiếp đó là triệu chứng triệu chứng căng cơ / đau đớn với tỉ lệ $25,4 \%$. Sự rối loạn các chất dẫn truyền thần kinh và rối loạn thần kinh tự chủ của RLLALT dẫn đến rối loạn sự co cớ, rối loạn sự phân bố máu ở các cơ quan làm xuất hiện các triệu chứng căng cơ / đau đớn. Các triệu chứng này thường khiến bệnh nhân thăm khám tại các chuyên khoa thần kinh hoăc đa khoa.

Nhóm triệu chứng không đặc hiệu khác. Ngoài triệu chứng thường gặp là triệu chứng hồi hộp, tim đập nhanh trong nhóm 22 triệu chứng, triệu chứng khó ngủ vì lo lắng hầu hết gặp ở bệnh nhân RLLALT (77,1\%). Ngoài ra, hai triệu chứng triệu chứng dể giật mình và khó tập trung cũng thường gặp ở bệnh nhân RLLALT với tỉ lệ lần lượt là $33,1 \%$ và $28,0 \%$. Nghiên cứu nhận thấy, nhiều triệu chứng khác cũng có thể xuất hiện trong bệnh cảnh của RLLALT. Rối loạn giấc ngủ là một rối loạn thường thấy ở các bệnh nhân rối loạn tâm thần. Bệnh nhân có RLLALT có sự rối loạn về số lượng và chất giấc ngủ. Nhiều nghiên cứu cho biết rối loạn giấc ngủ ở bệnh nhân RLLALT bao gồm khó bắt đầu ngủ, giảm thời gian ngủ, khó giữ được giấc ngủ và thức giấc khó ngủ lại.

\section{KẾT LUẬN}

Bệnh nhân RLLALT phần lớn là nữ $(55,9 \%)$, tuổi thường gặp là từ 30 đến 49 tuổi. Tuổi trung bình của nhóm bệnh nhân nghiên cứu là 46,98 \pm 14,27 . Mức độ lo âu thường gặp là nặng theo HAM-A $(50,8 \%)$. Phần lớn là chủ đề gia đình $(61,0 \%)$ và tai nạn bệnh tật $(58,5 \%)$. Triệu chứng trong nhóm kích thích thần kinh thực vật thường gặp là hồi hộp/ tim đập mạnh/ nhanh $(93,2 \%)$. Các triệu chứng tâm thần thường gặp nhất là triệu chứng chứng bồn chồn $(44,1 \%)$, triệu chứng căng dễ giật mình $(33,1 \%)$ và khó ngủ vì lo lắng $(77,1 \%)$. Các triệu chứng cơ thể thường gặp nhất là: vã mồ hôi $(60,2 \%)$, buồn nôn/khó chịu ở bụng (42,4\%), cảm giác tê cóng/kim châm (39,8\%).

\section{TÀI LIÊU THAM KHẢO}

1. Đinh Đăng Hòe (2000), Bài giảng chuyên đề tâm thần hoc. Rối loạn lo âu, Bộ môn tâm thần Đai hoc Y Hà Nôi.

2. Stein D.J. (2009), Textbook of Anxiety Disorders, American Psychiatric Publishing, Inc., Washington, DC.

3. Wittchen H.U., Jacobi F., Rehm J., et al. (2011). The size and burden of mental disorders and other disorders of the brain in Europe 2010. Eur Neuropsychopharmacol, 21(9), 655-679.

4. Nguyê̂n Kim Việt (2009), Lâm sang và điêuu tri các rối loạn lo âu, Bộ môn tâm thân - Đại học Y Hà Nội.

5. Hoffman D.L., Dukes E.M., and Wittchen H.U. (2008). Human and economic burden of generalized anxiety disorder. Depress Anxiety, 25(1), 72-90.

6. Revicki D.A., Brandenburg N., Matza L., et al. (2008). Health-related quality of life and utilities in primary-care patients with generalized anxiety disorder. Qual Life Res, 17(10), 1285-1294.

7. Dugas M.J., Freeston M.H., Ladouceur R., et al. (1998). Worry themes in primary GAD secondary GAD, and other anxiety disorders. J Anxiety Disord, 12(3), 253-261.

8. Papadimitriou G.N. and Linkowski P. (2005). Sleep disturbance in anxiety disorders. Int Rev Psychiatry, 17(4), 229-236.

\title{
STRESS Ở SINH VIÊN HÊ BÁC SĨ Y KHOA NĂM THỨ NHẤT TRƯỜNG ĐẠI HỌC Y HÀ NộI NĂM HỌC 2020-2021 VÀ MộT SỐ YẾU TỐ LIÊN QUAN
}

\section{TÓM TẮT}

Nghiên cứu nhằm xác định tỷ lệ stress và một số yếu tố liên quan đến stress ở sinh viên năm thứ nhất

*Trường Đại học Y Hà Nội

Chịu trách nhiệm chính: Lê Thị Vũ Huyền

Email: levuhuyen@hmu.edu.vn

Ngày nhận bài: 9.8.2021

Ngày phản biên khoa hoc: 5.10 .2021

Ngày duyệt bài: 14.10 .2021

\section{Lê Thị Vũ Huyền*, Nguyễn Thị Thu Thủy*}

hê bác sĩ y khoa trường Đai hoc $Y$ Hà Nôi năm học 2020-2021. Nghiên cứu mô tả cắt ngang trền 345 sinh viên, công cu để đánh giá stress là thang DASS 21. Kết quả cho thấy $42,6 \%$ sinh viên có stress. Trong đó stress mức độ nhẹ: $17,1 \%$, stress mức độ vừa: 13,9\%, stress mức độ nặng: 8,4\%, rất nặng: 3,2\%. Các yếu tố liên quan đến stress ở sinh viền năm thứ nhất hệ bác sĩ Y khoa là: xung đột với bạn cùng phòng, kết thúc một tình bạn, rắc rối với bố mẹ, sức khỏe giảm sút, thay đổi hành vi trong việc sử dụng rượu bia, thuốc lá hoặc chất gây nghiện, gia tăng việc 
học ở trường quá nhiều, điểm học không như mong đợi, chưa thích nghi được với cách học ở trường đại học

\section{SUMMARY \\ STRESS AMONG FIRST YEAR MEDICAL DOCTOR STUDENTS AT HANOI MEDICAL UNIVERSITY IN THE 2020-2021 ACADEMIC YEAR AND SOME ASSOCIATED FACTORS}

The study aimed to determine the proportion of students experiencing stress and some factors related to stress among first-year medical doctor students at Hanoi Medical University in the academic year 20202021. We conducted a cross-sectional study on 345 students and used the DASS 21 scale to assess the level of stress among students. Our results showed that $42.6 \%$ of students had stress $(17.1 \%$ with mild stress, $13.9 \%$ with moderate stress, $8.4 \%$ with severe stress, $3.2 \%$ with very severe stress). Factors associated with stress among first-year medical students included conflict with roommates, end of a friendship, trouble with parents, declining health, behavior change in substance use (alcohol, tobacco or drugs), enormously increased learning at school, marks not as expected, have not adapted to the way of studying at university.

Tư khóa: Stress, sinh viên năm thứ nhất hệ Bác sĩ Y khoa, yếu tố liên quan

\section{I. ĐĂT VẤN ĐỀ}

Theo Hans Selye stress là phản ứng sinh hoc không đặc hiệu của cơ thể trước những tác nhẩn gây căng thẳng ${ }^{1}$. Hiện nay tỷ lệ stress trên thế giới là khá cao đăc biệt trong môi trường y tế. Một nghiên cứu cắt ngang tai một trường đại hoc Y ở Ả rập Xê út cho thấy tỷ lệ căng thẳng của sinh viên là $63 \%{ }^{2}$. Tại việt nam nghiên cứu của Lê Hoàng Thanh Nhung trên sinh viên khoa $Y$ tế công cộng cho thây tỷ lệ stress ở sinh viên là 44,5\%33. Tại trường Đại học Y Hà Nội, nghiên cứu của Phạm Thị Huyền Trang năm 2013 cho kết quả sinh viên bị stress là $63,6 \%{ }^{4}$.

Stress ảnh hưởng tới cả sức khỏe thể chất và tinh thân, ảnh hưởng tới khả năng học tập và chất lượng cuộc sống thậm chí có thể gây ra các rối loan liên quan đến stress như là lo âu trầm cảm.

Sinh viên năm thứ nhất bắt đâu bước vào ngưỡng cửa trường đại học, việc thay đổi môi trường sống, phương pháp học tập ở đại học và học tập trong một môi trường đây áp lực như trường đại học Y Hà Nội cũng là những thách thức đối với các em. Tỷ lệ stress mà các em gặp phải ra sao, yếu tố nào là yếu tố nguy cơ làm tăng stress là một vấn đề lớn cân phải quan tâm. Hiện nay, hệ bác sĩ Y khoa chương trình đang thay đổi do đó việc tìm hiểu stress trên sinh viên hệ bác sĩ Y khoa năm thứ nhất và các yếu tố liên quan sẽ là cơ sở cho việc xây dựng được chương trình học tập, các biện pháp hố trợ sinh viên trên cơ sở đó giúp hạn chế hậu quả tiêu cực do sress gây nên. Với tất cả những lý do trên chúng tôi tiến hành nghiên cứu đề tài: "Stress ở sinh viên hê bác sĩ Y khoa năm thứ nhất trường đai hoc $Y$ Hà Nội năm học 2020-2021 và một số yếu tố liên quan"với 2 mục tiêu cụ thể sau:

1. Mô tả thực trạng stress của sinh viên hệ bác sĩ y khoa năm thứ nhất trường Đại học Y Hà Nội năm họ 2020-2021.

2. Mô tả một số yêu tố liên quan đên stress của sinh hệ bác sĩ y khoa năm thứ nhất trướng Đại học Y Hà Nôi năm học 2020-2021.

\section{II. ĐỐI TƯợNG VÀ PHƯƠNG PHÁP NGHIÊN CỨU}

1. Đối tượng nghiên cứu:

*Tiêu chuẩn lựa chon:

Sinh viên hê bác sỹ $Y$ khoa năm thứ nhất Trường Đại học Y Hà Nội năm học 2020-2021.

- Sinh viên đồng ý tham gia vào nghiên cứu.

*Tiêu chuẩn loai trừ:

- Sinh viên không hợp tác tham gia nghiên cứu.

- Sinh viên không có mặt trong thời gian nghiên cứu.

*Thời gian nghiên cứu:

- Thời gian nghiên cứu: Từ tháng 10/2020 đến tháng 06/2021.

- Thời gian thu thập số liệu: Từ tháng 03/2021 đến tháng 04/2021.

\section{Phương pháp nghiên cứu}

\section{Thiết kế nghiên cứu:}

Thiết kế nghiên cứu: Mô tả cắt ngang.

Cỡ mẫu và cách chọn mẫu. Nghiên cứu đã lấy toàn bô sinh viên năm thứ nhất ngành bác sỹ Y khoa trường đại học Y Hà Nội. Trên thực tế sau khi đã loại đi một số phiếu sót thông tin hoặc một số sinh viên từ chối không tham gia nghiên cứu, cõ mẫu cuối cùng là 345 sinh viên

Các biến số nghiên cứu

Các biến số về thông tin chung của đối tượng nghiên cứu

- Giới tính, điểm trung bình học tâp

Các biến số cho mục tiêu 1: Tỷ lệ stress của sinh viên

Các biến số và chỉ số cho mục tiêu 2

- Yếu tố cá nhân: giới, nơi sống trước khi vào đại học, đi làm thêm, khó khăn về tài chính, bạn thân, chia sẻ với bạn thân, tham gia các câu lạc bộ, hoạt động xã hội, tâp thể dục

- Các sự kiên xảy ra trong học kỳ vừa qua liên quan đến: Mối quan hệ giữa các cá nhân, cá nhân, vấn đề học tập

\section{Phương pháp thu thâp thông tin:}

Điều tra viên được tập huấn kỹ về kĩ năng, nội dung công việc. 
- Điều tra viên liên hệ phòng Đào tạo Đại học để xem lịch học của đối tượng nghiên cứu. Trển cơ sở lịch học, chọn thời điểm phù hợp nhất với đối tượng nghiên cứu để ít ảnh hưởng đến thời gian học tập của đối tượng nghiên cứu.

\section{Công cụ thu thập số liệu}

Bộ câu hỏi nghiên cứu bao gồm 3 phần:

Phần 1: Thông tin chung của đối tượng

Phần 2: Thang DASS 21 (Depression Anxiety Stress Scale 21) gồm 21 câu hỏi đánh giá trầm cảm- lo âu- stress. Trong nghiên cứu này chủ yếu tập trung đánh giá stress nên dựa vào tổng điểm của các câu hỏi thành phần gồm các câu $1,6,8,11,12,14,18$ rồi nhân hệ số 2 . Sau khi có kêt quả thì đánh giá stress dựa trên 5 mức độ: bình thường (0-14), nhe (15-18), vừa (19-25), nặng (26-33), rất nặng (>=34)

Phần 3: Các câu hỏi về những sự kiện xảy ra trong học kỳ vừa qua. Bao gồm các câu hỏi liên quan đển các sự kiện về: Mối quan hệ giữa các cá nhân, cá nhân, vấn đề học tập

3. Xử lý số liệu. Số liệu sau khi được làm sạch và được nhập vào Excel và phân tích bằng phần mềm SPSS 20. Nghiên cứu sử dụng phân tích đơn biến để xác định yếu tố liên quan đến stress trên sinh viên năm thứ nhất

4. Đaao đức nghiên cứu: Nghiên cứu được tiến hành với sự đồng ý của phòng Đào tạo Đại học, Viện đào tạo $Y$ học dự phòng và $Y$ tế công cộng, Bộ môn Y đức và tâm lý học Trường Đại học $Y$ Hà Nội.

Đối tượng nghiên cứu được cung cấp đầy đủ thông tin về mục đích, nội dung của nghiên cứu, tự nguyên tham gia bằng cách xác nhận vào bản thỏa thuận tham gia nghiên cứu, thông tin của đối tượng tham gia nghiên cứu hoàn toàn được giữ bí mật. Nếu đối tượng từ chối hoặc ngưng giữa chừng thì không bắt ép đối tượng tham gia nghiên cứu

\section{KẾT QUẢ NGHIÊN CỨU}

1. Đặc điểm chung về đôii tượng nghiên cứu

Bảng 1. Một số thông tîn chung về đôí tượng nghiên cứu

\begin{tabular}{|c|c|c|c|}
\hline \multicolumn{2}{|c|}{ Đặc điểm chung } & $\begin{array}{c}\text { Số học } \\
\text { sinh }\end{array}$ & $\begin{array}{c}\text { Tỷ lệ } \\
\text { \%o }\end{array}$ \\
\hline \multirow{2}{*}{ Giới } & Nam & 187 & 54,2 \\
\cline { 2 - 4 } & Nữ & 158 & 45,8 \\
\hline \multirow{2}{*}{$\begin{array}{c}\text { Hợ } \\
\text { lực }\end{array}$} & Giỏi & 24 & 7,0 \\
\cline { 2 - 4 } & Khá & 190 & 55,1 \\
\cline { 2 - 4 } & Trung bình & 94 & 27,2 \\
\cline { 2 - 4 } & Dưới trung bình & 12 & 3,5 \\
\hline N & & 345 & \\
\hline
\end{tabular}

Sinh viên nam nhiều hơn sinh viên nữ chiếm tỷ lệ $54,2 \%$. Học lực của sinh viên tính theo quy chế đào tạo tín chỉ sinh viên đạt học lực loai khá chiếm đa số với tỷ lệ $55,1 \%$, vẫn còn 3,5\% đạt học lực dưới trung bình

2. Thực trạng stress ở sinh viên hệ bác sĩ Y khoa năm thứ nhất

Bảng 1. Thức trang stress của sinh viên hê bác sĩ $Y$ khơ nằm thứ nhất

\begin{tabular}{|c|c|c|}
\hline & $\mathbf{n}$ & $\mathbf{\%}$ \\
\hline Có stress & 147 & 42,6 \\
\hline Không stress & 198 & 57,4 \\
\hline \multicolumn{2}{|c|}{ Các mức độ stress } \\
\hline Stress mức độ nhẹ & 59 & 17,1 \\
\hline Stress mức độ vừa & 48 & 13,9 \\
\hline Stress mức độ nặng & 29 & 8,4 \\
\hline Stress mức độ rầt nặng & 11 & 3,2 \\
\hline N & 345 & 100 \\
\hline
\end{tabular}

Tỷ lệ sinh viên bị stress là 42,6\%. Trong đó mức độ stress nhẹ và vừa là chủ yếu chiếm tỷ lệ $17,1 \%$ và $13,9 \%$. Tỷ lệ sinh viên stress nặng chiếm $8,4 \%$ và rất nặng chiếm $3,2 \%$

2. Một số yếu tố liên quan đến stress của sinh viên hệ bác sĩ Y khoa năm thứ nhất Bảng 2. Một số yếu tố liên quan đến stress của sinh viên

\begin{tabular}{|c|c|c|c|c|}
\hline \multirow{2}{*}{\multicolumn{2}{|c|}{ Các yếu tố liên quan }} & \multicolumn{2}{|c|}{ Stress } & \multirow{2}{*}{ OR 95\%CI } \\
\hline & & Stress n(\%) & Không stress n(\%) & \\
\hline \multicolumn{5}{|c|}{ Các thông tin cá nhân } \\
\hline \multirow{2}{*}{ Giới } & Nam & $80(54,4)$ & $107(54,0)$ & \multirow{2}{*}{$1,02(0,66-1,56)$} \\
\hline & Nũ̃ & $67(45,6)$ & $9146,0)$ & \\
\hline \multirow{4}{*}{$\begin{array}{l}\text { Nơi sống trước khi } \\
\text { vào đại học }\end{array}$} & Vùng nông thôn & $67(45,6)$ & $91(46,0)$ & $0,89(0,49-2,27)$ \\
\hline & $\begin{array}{l}\text { Thành phố trực } \\
\text { thuộc tỉnh }\end{array}$ & $38(25,9)$ & $44(22,2)$ & $0,80(0,40-2,05)$ \\
\hline & Thị trấn, thị xã & $28(19,0)$ & $45(22,7)$ & $0,60(0,54-2,90)$ \\
\hline & $\begin{array}{l}\text { Thành phố trực } \\
\text { thuộc trung ương }\end{array}$ & $14(9,5)$ & $18(9,1)$ & 1 \\
\hline \multirow{2}{*}{ Đi làm thêm } & Có & $40(27,2)$ & $47(23,7)$ & \multirow{2}{*}{$1,20(0,37-1,96)$} \\
\hline & Không & $107(72,8)$ & $151(76,3)$ & \\
\hline Khó khăn về tài & Có & $45(30,6)$ & $51(25,8)$ & $1,27(0,80-2,04)$ \\
\hline
\end{tabular}




\begin{tabular}{|c|c|c|c|c|}
\hline chính & Không & $102(69,4)$ & $147(74,2)$ & \\
\hline \multirow{2}{*}{ Có bạn thân } & Không & $23(15,6)$ & $21(10,6)$ & \multirow{2}{*}{$1,56(0,83-2,95)$} \\
\hline & Có & $124(84,4)$ & $177(89,4)$ & \\
\hline Chia sẻ với bạn & Không & $48(32,7)$ & $52(26,3)$ & \multirow{2}{*}{$1,36(0,85-2,17)$} \\
\hline thân & Có & $99(67,3)$ & $146(73,7)$ & \\
\hline \multirow{2}{*}{$\begin{array}{l}\text { Tham gia các câu } \\
\text { lạc bộ, các hoạt } \\
\text { động xã hội }\end{array}$} & Không & $39(26,5)$ & $49(24,7)$ & \multirow{2}{*}{$1,10(0,67-1,79)$} \\
\hline & Có & $108(73,5)$ & $149(75,3)$ & \\
\hline \multirow[t]{2}{*}{ Tập thế dục } & Không & $55(37,4)$ & $65(32,8)$ & \multirow{2}{*}{$1,22(0,78-1,91)$} \\
\hline & Có & $92(62,6)$ & $133(67,2)$ & \\
\hline \multicolumn{5}{|c|}{ Giữa các cá nhân } \\
\hline \multirow{2}{*}{$\begin{array}{l}\text { Xung đột với bạn } \\
\text { thân hoăc bạn } \\
\text { cùng phòng }\end{array}$} & Có & $35(23,8)$ & $15(7,6)$ & \multirow{2}{*}{$3,81(1,99-7,29)$} \\
\hline & Không & $112(76,2)$ & $183(92,4)$ & \\
\hline \multirow{4}{*}{\begin{tabular}{|c|} 
Cãi nhau với bạn \\
trai/bạn gái (người yêu \\
Kết thúc một mối \\
quan hề gần gũi \\
(tình bạn) \\
\end{tabular}} & Có & $32(21,8)$ & $30(15,2)$ & \multirow{2}{*}{$1,56(0,90-2,71)$} \\
\hline & Không & $115(78,2)$ & $168(84,8)$ & \\
\hline & Có & $20(13,6)$ & $14(7,1)$ & \multirow{2}{*}{$2,07(1,01-4,25)$} \\
\hline & Không & $127(86,4)$ & $184(92,9)$ & \\
\hline \multirow{2}{*}{ Rắc rôi với bố mẹ } & Có & $15(10,2)$ & $9(4,5)$ & $2,39(1,01-5,62)$ \\
\hline & Không & $132(89,8)$ & $189(95,5)$ & \\
\hline \multicolumn{5}{|c|}{ Cá nhân } \\
\hline \multirow{2}{*}{$\begin{array}{l}\text { Giảm sức khỏe } \\
\text { bản thân, chấn } \\
\text { thương/ốm nặng }\end{array}$} & Có & $48(32,7)$ & $41(20,7)$ & \multirow[b]{2}{*}{$1,86(1,14-3,02)$} \\
\hline & Không & $99(67,3)$ & $157(79,3)$ & \\
\hline \multirow{2}{*}{$\begin{array}{l}\text { Thay đối trong sử } \\
\text { dụng rượu, bia, } \\
\text { thuốc lá hoặc chất } \\
\text { gây nghiện }\end{array}$} & Có & $33(22,4)$ & $25(12,6)$ & \multirow[b]{2}{*}{$2.00(1,13-3,35)$} \\
\hline & Không & $114(77,6)$ & $173(87,4)$ & \\
\hline \multirow{2}{*}{$\begin{array}{l}\text { Một thành viên } \\
\text { trong gia đình bị } \\
\text { bệnh nặng }\end{array}$} & Có & $19(12,9)$ & $14(7,1)$ & \multirow{2}{*}{$1,95(0,944-4,03)$} \\
\hline & Không & $128(87,1)$ & $184(92,9)$ & \\
\hline \multirow{2}{*}{\begin{tabular}{|l|} 
Cái chết của môtt \\
thành viên gia đînh \\
\end{tabular}} & Có & $11(7,5)$ & $7(3,5)$ & \multirow{3}{*}{$2.21(0,83-5,84)$} \\
\hline & Không & $136(92,5)$ & $191(96,5)$ & \\
\hline & & Học tập & & \\
\hline \multirow{2}{*}{$\begin{array}{l}\text { Gia tăng việc học ở } \\
\text { trướng quá nhiều }\end{array}$} & Có & $62(42,2)$ & $46(23,2)$ & \multirow{2}{*}{$2,41(1,51-3,84)$} \\
\hline & Không & $85(57,8)$ & $152(76,8)$ & \\
\hline \multirow{2}{*}{$\begin{array}{l}\text { Điểm học không } \\
\text { như mong đợi }\end{array}$} & Không & $125(85,0)$ & $151(76,3)$ & \multirow{2}{*}{$1,77(1,01-3,09)$} \\
\hline & Không & $22(15,0)$ & $47(23,7)$ & \\
\hline \multirow{2}{*}{$\begin{array}{c}\text { Thích nghi được } \\
\text { cách học ở trướng } \\
\text { đại học }\end{array}$} & Không & $89(60,5)$ & $77(38,9)$ & \multirow[b]{2}{*}{$2,41(1,56-3,73)$} \\
\hline & Có & $58(39,5)$ & $121(61,1)$ & \\
\hline Nợ môn & $\begin{array}{c}\text { Có } \\
\text { Không }\end{array}$ & $\begin{array}{c}7(4,8) \\
140(95,2)\end{array}$ & $\begin{array}{c}10(5,1) \\
188(94,9)\end{array}$ & $0,94(0,35-2,53)$ \\
\hline
\end{tabular}

Kết quả phân tích đơn biến ở bảng 2 cho thấy các thông tin cá nhân không liên qua đến tình trạng stress trên sinh viên hệ bác sĩ Y khoa năm thứ nhất

Các sự kiện xảy ra trong học kỳ vừa qua thì thấy:

Những sự kiện liên quan đến mối quan hệ giữa các cá nhân. Xung đột với bạn cùng phòng có nguy cơ mắc stress cao gấp 3,813 $(1,992-7,295)$ những sinh viên không có xung đột với bạn cùng phòng. Kết thúc một mối quan hệ (tình bạn) có nguy cơ mắc stress cao gấp
2,070 (1,008-4,250) sinh viên khác. Sinh viên gặp rắc rối với bố me có nguy cơ mắc stress cao gấp $2,386(1,014-5,616)$ sinh viên không gặp rắc rối với bố mẹ.

Những sự kiện liên quan đến cá nhân: Sinh viên gặp những vấn đề về sức khỏe (giảm sức khỏe, chấn thương...) có nguy cơ mắc stress cao gấp $1,857(1,141-3,021)$ sinh viên không 
gặp những vấn đề về sức khỏe. Những sinh viên có thay đổi trong việc sử dụng rượu, bia, thuốc lá hoặc các chất gẩy nghiển có nguy cơ mắc stress cao gấp 2,003 $(1,132-3.345)$ sinh viên không có thay đổi về những hành vi này.

Về vấn đề học tập: Những sinh viên cho rằng việc học ở trường là quá nhiều và không có thời gian nghỉ ngơi có nguy cơ mắc stress cao gấp $2,410(1,514-3,836)$ sinh viên không cho là việc học ở trường quá nhiều không có thời gian nghỉ ngơi. Sinh viên có kết quả học tập không như mong đơi có nguy cơ mắc stress cao gấp 1,769 (1.011-3,093) sinh viên có kết quả học tập như mong muốn. Sinh viên cho rằng vẫn chưa thích nghi được cách học tập ở trường đại học có nguy cơ gặp stress cao gấp $2,411(1,558-3,733)$ sinh viên đã thích nghi được việc hooc ở đại học.

\section{BÀN LUẬN}

1. Tỷ lệ stress: Tỷ lệ stress trong nghiên cứu của chúng tôi là $42,6 \%$ tương đồng với kết quả nghiên cứu của Lê Hoàng Thanh Nhung trên sinh viên khoa $Y$ tế công cộng cho thấy tỷ lệ stress ở sinh viên là 44,5\%. Tuy nhiên cao hơn kết quả nghiên cứu của Nguyễn Hoàng Nguyên Stress trên sinh viên hệ bác sĩ của trường đại học Y Hà Nội năm học 2018-2019 là 33,9\% ${ }^{5}$ và thấp hơn nghiên cứu của Phạm Thị Huyên Trang năm 2013 trên sinh viên $Y$ là $63,5 \%{ }^{4}$. Sự khác nhau này theo chúng tôi là do nghiên cứu này sử dụng cùng thang đo với chúng tôi nhưng lại tiến hành ở các thời gian khác nhau. Nghiên cứu của chúng tôi tiến hành đúng thời điểm vừa hết dãn cách xã hội do dịch covid các em mới đi học lại còn chủ yểu học ở nhà qua internet ít nhiều cũng gây căng thẳng cho các em. Còn kết quả khác với nghiên cứu của Phạm Thị Huyền Trang thì có thể là do công cụ đo khác nhau nên có thể có tỷ lệ stress là khác. Khi xem xét các mức độ stress thì thây: Tỷ lệ sinh viên stress nặng $(8,4 \%)$ và rất nặng là $3,2 \%$ thấp hơn nghiên cứu về sinh viên Y khoa tại Ả Rập Saudi, Pakistan,... cho thấy tỷ lệ stress ở mức độ nặng trở lên chiếm hơn $20 \%{ }^{2}$. Sự chênh lệch này có thể do khác nhau về đối tượng nghiên cứu, văn hóa, điều kiên kinh tế

2. Một số yếu tố liên quan đến stress ở sinh viên năm thứ nhất:

Các yếu tố thông tin chung. Những thông tin chung được đưa vào mô hình hồi quy logistic để tính toán: giới, nơi sống trước khi vào đại học, khó khăn về tài chính, đi làm thêm, có bạn thân, chia sẻ với bạn thân, tham gia hoạt động xã hội, tập thể dục đều không liên quan đến tình trạng stress trên sinh viên năm thứ nhất. Kết quả này tương đồng nghiên cứu của Triệu Thị Đào như giới, sống một mình hay cùng người thân, đi làm thêm, có bạn thân, chia sẻ các vấn đề trong học tập, cuộc sống với bạn thân không có liên quan đến stress. Nhưng khác với chúng tôi yếu tố không tham gia các câu lạc bộ có liên quan đến stress $O R=4,17(1,85-$ $9,43)^{6}$. Đặc biệt là có bạn thân, nhận được sự động viên chia sẻ của bạn, thói quen tập thể dục là yếu tố bảo vệ sinh viên khỏi stress là kết quả nghiên cứu của Trần Thị Thanh Hương và Vũ Dũng?.

- Các sự kiện xảy ra trong học kỳ vừa qua thì thấy:

Những vấn đề liên quan đến mối quan hệ giữa các cá nhân. Kết quả nghiên cứu của chúng tôi cho thấy xung đột với bạn cùng phòng, kết thúc một mối quan hệ (tình bạn) là yếu tố nguy cơ làm tăng stress lển từ 2-3 lần. Sự tăng stress do các sự kiện trong mối quan hệ phù hợp với đặc điểm của sinh viên đi học xa nhà dẫn đến nhiều sự thay đổi đặc biệt là thay đổi trong các mối quan hê và đối với lứa tuổi thanh niên sinh viên mối quan hê bạn bè còn đóng vai trò rất quan trọng trong đời sống của các em. Ngoài ra đối với sinh viên hệ bác sĩ Y khoa năm thứ nhất năm học 2020-2021 thì rắc rối với bố me còn làm tăng nguy cơ gặp stress ở các em. Như' vậy đối với sinh viên năm thứ nhất gia đình vẫn còn ảnh hưởng rất lớn đối với các em.

Những vấn đề liên quan đến cá nhân: Sự xuất hiện các sự kiện liên quan đến bản thân cũng là một trong các yếu tố liên quan đến stress: Có vấn đề về sức khỏe (giảm sức khỏe, chấn thương), có thay đổi trong việc sử dụng rượu, bia, thuốc lá hoặc các chất gây nghiên có nguy cơ mắc stress cao gấp 1,8-2 lần. Kết quả này tương đồng với kết quả nghiên cứu của Đăng Đức Nhu suy giảm vấn đề sức khỏe bản thân là yếu tố làm tăng stress ở sinh viên $\mathrm{OR}=2,82(1,65-4,83)^{8}$.

Về vấn đề học tâp: Học tâp là vấn đề lớn mà sinh viên năm thứ nhất phải đối mặt do thay đổi môi trường học tập các thây cô, môn học và đặc biệt phương pháp học tập khác hẳn ở phổ thông. Những vấn đề liên quan đến học tập mà chúng tôi tìm thấy là nguy cơ làm tắng stress của sinh viên năm thứ nhất là: Việc học ở trường là quá nhiều không có thời gian nghỉ ngơi, kết quả học tập không như mong đợi. Kết quả này tương đồng với nghiên cứu của Đặng Đức Nhu: Xếp loại thấp hớn mong đợi $\mathrm{OR}=1,64(1,08$ $2,49)^{8}$ và Triệu Thị Đào: Thiếu tự tin với điểm học tập của mình OR $=15,1(8,5-25,69)^{6}$. Ngoài 
ra chưa thích nghi được cách học tập ở trường đại học cũng là yếu tố nguy cơ làm tăng stress gấp 2,411 sinh viên đã thích nghi được việc học ở đại học

\section{KẾT LUÂ̂N}

Tỷ lệ sinh viên năm thứ nhất hệ bác sĩ $Y$ khoa gặp stress là $42,6 \%$. Trong đó mức độ nặng và rẩt năg chiếm tỷ lệ $8,4 \%$ và $3,2 \%$. Các yếu tố liên quan có thể kể đến các yếu tố: xung đột với bạn cùng phòng, kết thúc một tình bạn, rắc rối với bố mẹ, sức khỏe giảm sút, thay đổi hành vi trong việc sử dụng rượu bia, thuốc lá hoặc chất gây nghiện, gia tăng việc học ở trường quá nhiề, điểm học không như mong đợi, chưa thích nghi được với cách học ở trường đại học

\section{TÀI LIÊU THAM KHẢO}

1. Selye H. Forty years of stress research: principal remaining problems and misconceptions. Can Med Assoc J. 1976;115(1):53-56.
2. Abdulghani HM, AlKanhal AA, Mahmoud ES, Ponnamperuma GG, Alfaris EA. Stress and Its Effects on Medical Students: A Cross-sectional Study at a College of Medicine in Saudi Arabia. J Health Popul Nutr. 2011;29(5):516-522.

3. Lê Hoàng Thành Nhung. Stress và các yếu tố liên quan ở sinh viên khoa Y tế công cộng Đại học Y dước thành phố Hồ Chính Minh. Tap chí Ý học thực hành. Số 1 . Năm 2018

4. Phạm Thị Huyên Trang. Thực trạng stress trong sinh viên trường Đại học Y hà Nội 2013.

5. Nguyển Hoàng Nguyền. Trầm cảm, lo âu và stress ở sinh viên hệ bác sĩ trường Đại học Y Hà Nội năm học 2018-2019 và một số yếu tố liên quan.

6. Triệu Thi Đào, 2016 thực trang và các yếu tố liên quan đến stress của sinh viên năm thứ ba trường đại học y hà nội.

7. Trân Thị Thanh Hương, Vũ Dũng. Thực trạng của sinh viên điêu dưỡng năm 2,3 của trường Đ̇ại học Thăng Long, năm 2015 và một số yếu tố liên quan. Tap chí Y học Việt Nam. số chuyên đề. năm 2017

8. Đăng Đức Nhu. Thức trang và các yếu tố liên quan đến stress của sinh viên năm thứ ba trường Đaai học Công nghệ đại học quốc gia Hà Nội năm 2015. Tạp chí Y học Dự phòng. số 1. Năm 2016.

\section{ĐÁNH GIÁ KẾT QUẢ NộI SOI NGƯợC DÒNG TÁN SỎI NIỆU QUẢN 1/3 DƯớI TẠI BỆNH VIỆN HỮU NGHI VIỆT ĐỨC}

\section{TÓM TẮT.}

Mục tiêu: đánh giá kết quả điều trị, những yếu tố ảnh hưởng đến kết quả điều trị và tỷ lệ tai biến, biến chứng của phương pháp nội soi ngược dòng tán sỏi niệu quản $1 / 3$ dưới. Đối tượng và hương pháp: Mô tả tiến cứu trên 81trường hợp có sỏi niệu quản 1/3 dưới được nội soi tán sỏi ngược dòng bằng laser Holmium tại khoa Phẫu thuật tiết niệu, Bệnh viện Hữu nghị Việt Đức từ tháng 6/2020 - 6/2021. Kết quả: 81 BN gồm 49 nam $(60,5 \%)$ và 32 nữ $(39,5 \%)$. Tuổi trung bình 47,9 $\pm 14,4$ tuổi (22-78). Sói NQ phải $43,2 \%$, sỏi NQ trái $56,8 \%$. Mức độ ứ nước thận trước mổ: 4 đài bể thận bình thường $(4,9 \%) ; 59$ độ I $(72,8 \%) ; 11$ độ II $(13,6 \%) ; 7$ độ III $(8,6 \%)$. Kích thước sởi trung bình: $9,72 \pm 3,76 \mathrm{~mm}(3-25 \mathrm{~mm})$. Thời gian phẫu thuâtt trung bình: $31,7 \pm 12,5$ phút $(10-65$ phút). Kết quả khi ra viện: Thành công $98,8 \%$, trong đó $88,9 \%$ đạt kết quả tổt, thất bại 1 ca $(1,2 \%)$ do sói chạy lên thận. Thời gian nằm viện trung bình: $4,06 \pm 1,93$ ngày (3-14 ngày). Theo dõi sau mổ 1tháng: mức độ giãn đài bể thận được cải thiện và tỷ lệ sạch sỏi đạt $100 \%$. Kích thước sỏi, tình trạng niệu

\footnotetext{
*Trường Đại học Y Hà Nội

**Bênh viển Việt Đức

Chịu trách nhiệm chính: Nguyễn Thế Thịnh

Email: ntthinhqn@gmail.com

Ngày nhận bài: 11.8.2021

Ngày phản biên khoa học: 6.10.2021

Ngày duyệt bài: 14.10 .2021
}

\section{Nguyễn Thế Thịnh*, Đỗ Trường Thành**}

quản và mức độ ứ nước thận ảnh hưởng đến kết quả tán sỏi. Tuổi, giới, số lượng sỏi không ảnh hưởng đến kết quả tán sỏi. Kết luận: Tán sỏi niệu quản ngược dòng bằng Laser Holmium là phương pháp an toàn, hiệu quả trong điều trị sỏi niệu quản $1 / 3$ dưới.

Tư khóa: sỏi niệu quản 1/3 dưới, tán sỏi nội soi ngược dòng, holmium laser.

\section{SUMMARY \\ EVALUATE RESULT'S URETEROSCOPY \\ LITHOTRIPSY BY HOLMIUM LASER AT VIETDUC UNIVERSITY HOSPITAL}

Objectives: to evaluate the treatment results, the factors affecting the outcome and the rate of complications of the Holmium YAG URL. Subjects and methods: Prospective study on 81 cases of lower third ureteral lithiasis treated with ureteroscopy with Holmium laser lithotripsy in Department of Urology, Viet Duc university Hospital between 6/20206/2021. Results: 49 males $(60,5 \%)$ and 32 females $(39,5 \%)$ with the everage age of $47,9 \pm 14,4$ (range from 22 to 78 years old). Right ureteral stones: $43,2 \%$; Left ureteral stones: $56,8 \%$. Estimate thehydronephrosison preoperative includes: 4 normal $(4,9 \%) ; 59$ grade I $(72,8 \%) ; 11$ grade II $(13,6 \%)$ and 7 grade III $(8,6 \%)$. Mean size stone: $9,72 \pm 3,76 \mathrm{~mm}$ (from 3 to 25 millimeters). Average operative time: $31,7 \pm 12,5$ minutes (from 10 to 65 minutes). Success rate at dischage: $98,8 \%$, in which $88,9 \%$ had good result. One failed case $(1,2 \%)$ due to the migration of the stone to the kidney. At 1 month follow up, the 